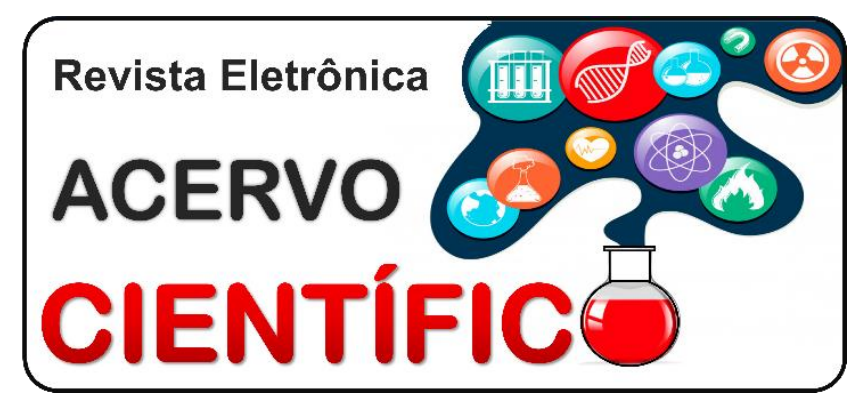

\section{REVISÃO BIBLIOGRÁFICA}

Recebido em: 6/2020

Aceito em: $7 / 2020$

Publicado em: 12/2020

\title{
Fundamentos da criminalística: um estudo epistemológico da fundamentação investigativa criminal
}

\author{
Fundamentals of criminalistics: an epistemological study of criminal investigative grounds
}

\author{
Fundamentos de criminalística: un estudio epistemológico de fundamentos de \\ investigación criminal
}

\author{
Mauro Lúcio Batista Cazarotti*.
}

\begin{abstract}
Resumo: $O$ presente trabalho tem como objeto de estudo a criminalística, ciência pela qual é realizada perícia. O questionamento que se faz por este objeto é que quais são seus fundamentos e contexto histórico, seu surgimento se deu-se pelo conhecimento ou necessidades práticas? Sendo assim como referencial teórico foram realizados levantamentos bibliográficos acerca do objeto de estudo e feito às devidas observações e agregado conhecimento na pesquisa. O estudo bibliográfico deu um subsídio para aprofundar o conhecimento em seu contexto histórico, evolução, conceito de criminalística, trabalho pericial e também sobre a aplicação na contemporaneidade. Foram discutidos conceitos de Garrido RG e Giovanelli A (2009), Braz JAC (2013) e Lino D e Mastunaga LH (2018), dentre outros. Por fim, é de suma importância a análise técnica e conceitual sobre a criminalística muitas vezes confundida com criminologia, apesar de muito parecidas, porém com ofício de trabalho diferente, conclui-se a importância do conhecimento sobre criminalística e seus fatores que podem auxiliar no trabalho operacional de agentes da área.
\end{abstract}

Palavras-chave: Criminalística fundações criminais, Experiência forense, Desenvolvimentos criminais.

\begin{abstract}
The present work has as object of study the criminalistics, science for which expertise is performed. The question that is asked for this object is that what are its foundations and historical context, its emergence if it was due to knowledge or practical needs? Thus, as a theoretical reference, bibliographical surveys were made about the object of study and made to the due observations and added knowledge in the research. The bibliographic study provided a subsidy to deepen the knowledge in its historical context, evolution, concept of criminalistics, expert work and also about its application in contemporary times. Concepts by Garrido RG e Giovanelli A (2009), Braz JAC (2013) e Lino D e Mastunaga LH (2018) among others, were discussed. Finally, technical and conceptual analysis of criminalistics, which is often confused with criminology, is of utmost importance, despite being very similar, but with a different job, it concludes the importance of knowledge about criminalistics and its factors that can help in the work operational area agents.
\end{abstract}

Keywords: Criminalistics criminal foundations, Forensic experience, Criminal developments.

Resumen: El presente trabajo tiene como objeto de estudio la criminalística, ciencia por la cual se realiza la experiencia. La pregunta que se hace para este objeto es: ¿cuáles son sus fundamentos y contexto histórico,

${ }^{1}$ Centro Universitário Estácio Ribeirão Preto (UNIESA), Ribeirão Preto - SP. *E-mail: cazarotti@edu.uniube.br 
su apariencia si se debiera a conocimientos o necesidades prácticas? Así, como referencia teórica, se realizaron encuestas bibliográficas sobre el objeto de estudio y las debidas observaciones y el conocimiento agregado de la investigación. El estudio bibliográfico proporcionó subsidios para profundizar el conocimiento en su contexto histórico, evolución, concepto de criminalística, trabajo especializado y también sobre su aplicación en los tiempos contemporáneos. Se discutieron los conceptos de Garrido RG e Giovanelli A (2009), Braz JAC (2013) e Lino D e Mastunaga LH (2018) entre otros. Finalmente, el análisis técnico y conceptual de la criminalística, que a menudo se confunde con la criminología, es extremadamente importante, a pesar de ser muy similar, pero con un trabajo diferente, concluye la importancia del conocimiento sobre la criminalística y sus factores que pueden ayudar en trabajo operacional. agentes del área.

Palabras clave: Criminalística fundaciones penales, Experiencia forense, Desarrollos criminales.

\section{INTRODUÇÃO}

De acordo com Sebastiany AP, et al. (2013), a perícia forense é um campo interdisciplinar que envolve física, biologia, química, matemática e outras ciências, projetado para apoiar investigações relacionadas à justiça civil e criminal. Dentro dela está a Química Forense cuja função tem destaque e mérito.

Porém com a diversificação dos ramos e o avanço da ciência, como a Química, a Biologia e a Física, percebeu-se necessidade de um maior direcionamento uma especialização, o que fez com que outros profissionais passassem a ser consultados (SEBASTIANY AP, et al., 2013).

Neste sentido pode-se definir que a Criminalística não é somente uma ciência, mas uma aplicação do conhecimento de diversas Ciências e Artes, por isso o estudo interdisciplinar é importante para criminologia (DOREA LE, 2006).

Algumas pessoas acreditam que a criminalística tem origem dentro da medicina legal (CODEÇO AG, 1991). Outras acreditam que a criminalística advém que da junção com outras áreas e desenvolve a criminologia contemporânea (DOREA LE, 2006).

Em seguida, é necessária uma nova disciplina de pesquisa que irá orientar a análise e interpretação dos vestígios encontrados na cena do crime. Assim, surgiram os criminologistas, que se utiliza de uma ciência independente criada para dar suporte aos departamentos de polícia e judiciário no esclarecimento de casos criminais (RABESCHINI AG, 2014).

Não se deve olvidar que é de suma importância a análise técnica e conceitual da criminalística, justificase este estudo pela elucidação e principalmente com o propósito de distingui-la da criminologia, ciência afim, mas que com aquela não se confunde. Desta feita, o presente artigo tem como objetivo de evidenciar qual o objeto de estudo da criminalística, e consequentemente elucidar as justificativas para o surgimento de tal ciência, seus fundamentos e como esta teve evolução diante de diversos contextos históricos, desde o seu surgimento até a contemporaneidade.

\section{REVISÃO BIBLIOGRÁFICA}

\section{Criminalística}

Conforme Zarzuela JL e Aragão F (1999), descreve que, os criminosos podem ser divididos em duas etapas: a primeira é a busca da verdade por métodos primitivos, mágicos ou por meio da tortura, visto que, na maioria dos casos, é impossível confessar espontaneamente a culpa ao réu; No segundo estágio, a verdade é buscada por meio de métodos racionais, estabelecendo assim o fundamento científico da criminologia e descartando a crença em milagres e magia.

\section{Evolução}

Em 1913, por iniciativa do Dr. Rafael de Sampaio Vidal, homem de visão e Secretário de Justiça e Segurança do Estado de São Paulo, o Professor Rudolph Archibald Reiss, diretor do Laboratório de Polícia 
Técnica e titular da cátedra de Polícia Científica da Universidade de Lausanne, na França, foram convidados para realizar uma série de conferências 21 didáticas para as autoridades policiais daquele Estado, a fim de dar maior conhecimento da questão e, ao mesmo tempo, solidificar a questão da Criminalística no país, abrindo novos horizontes àqueles ligados ao assunto (ESPINDOLA A, 2002).

O espaço geográfico, enquanto contexto de estudo para análise criminal, tem sido objeto de investigação desde 1833 com André-Michel Guerry em Essai sur la statistique morale de la France, onde o autor estudou a relação entre crime e aspectos sociodemográficos a partir da distribuição de diversas populações em relação aos segmentos territoriais que dividem a França. Outro autor pioneiro neste estudo foi Adolphe Quetelet, que buscou investigar, no século XIX (LINO D e MASTUNAGA LH, 2018).

Assim é que a "criminalística", termo oriundo da Escola Alemã se instala no Brasil, nascendo da necessidade de realizar os exames de corpo de delito e necroscópicos nos Estados brasileiros (FRANÇA GV, 2001).

\section{Conceitos de Criminalística}

Muitos confundem criminalística com ciência forense, o termo ciência forense não é sinônimo de ciência criminal em qualquer lugar do mundo. Para Gialamas DM (2000), a ciência forense deve ser definida como a aplicação da ciência a tópicos ou questões legais, civis, criminais e até administrativas. Portanto, a criminologia será apenas uma das disciplinas da ciência forense.

Nesse sentido, Rabello E (1996) tem por objeto a descoberta do crime, bem como a identificação de seus autores. Ainda em busca de uma definição ampla, faz uma conceituação mais abrangente, abordando vários aspectos da matéria. Dessa forma as matérias anônimas que integrada os diferentes ramos da área técnicacientífico, auxiliam e informativa das atividades policiais e judiciárias de investigação criminal, tendo por objeto o estudo dos vestígios materiais extrínsecos à pessoa física, no quer tiver de útil à elucidação e à prova das infrações penais e, ainda, à identificação dos autores respectivos" o que diz a Enciclopédia Saraiva de Direito sobre Criminalística (RABELLO E, 1996).

\section{Trabalho Pericial}

A Perícia Oficial Brasileira de Natureza Criminal surgiu da necessidade de realização dos exames médicolegais, sendo uma função exclusivamente estatal, tanto no aspecto processual, como no administrativo. É uma das provas admitidas na legislação brasileira, sendo regulada pelo Código de Processo Penal (1941) conforme, sendo que o art. 158 determina que "Quando a infração deixar vestígios será indispensável o exame de corpo de delito, direto ou indireto, não podendo supri-lo a confissão do acusado" (CAPEZ F, 2014)

A fim de que as investigações sejam realizadas da melhor forma possível, possibilitando o descobrimento do autor e dos fatos do crime, é necessário que haja uma preservação do local de crime, desde o acontecimento até a chegada dos peritos. Em aplicações práticas, podemos analisar esse fator a partir da ótica de Blume A (2018), que visa buscar argumentos sobre a atuação de peritos em tribunais. As autoridades policiais esperam que os especialistas sejam apenas assistentes do chefe de polícia. Algumas pessoas insistem que os especialistas são testemunhas técnicas; no final, os especialistas são convidados a servir como assistentes dos juízes.

Conforme Braz JAC (2013), enfatiza a partir do momento que tal preservação da cena do crime ocorre e que os peritos realizam seu trabalho com boas condições, aumenta-se a possibilidade de se reunir o melhor conjunto probatório possível, dando uma boa base para a ação penal e para o devido processo legal.

A importância dessa conservação do local do crime fica clara quando o Código de Processo Penal indica que o Delegado de Polícia Civil deve-se dirigir ao local da infração penal providenciando para que não se alterem o estado e a conservação das coisas (CAPEZ F, 2014). O exame realizado por técnico ou pessoa de comprovada aptidão e idoneidade profissional, para verificar e esclarecer um fato, ou estado ou a estimação da coisa que é objeto de litígio ou de processo, que com um deles tenha relação ou dependência, a fim de concretizar uma prova ou oferecer o elemento de que necessita a justiça para poder julgar (ARAÚJO LA, 2004) 
No crime, a perícia vai obedecer às normas estabelecidas pelo Código de Processo Penal (Arts. 158 e seguintes), devendo ser efetuada o mais breve possível, antes que desapareçam os vestígios. De acordo com Espindola A (2007), o Perito Oficial pode ser, tanto o Perito Criminal, como o Perito Médico Legista; e é o profissional, aprovado em concurso público de provas e títulos, responsável pela realização da Perícia Oficial Brasileira de Natureza Criminal, conforme o art. 159, do Código de Processo Penal.

O exame de corpo de delito e outras perícias serão realizados por Perito Oficial de Natureza Criminal, portador de diploma de curso superior. O Laudo Pericial, materialização do exame de corpo de delito, é uma peça escrita em que o Perito Oficial descreve, de forma mais objetiva possível, seus estudos, observações e pesquisas a respeito da perícia realizada; e responde aos quesitos apresentados pelo juiz, Ministério Público, assistente de acusação, ofendido, querelante e acusado (CAPEZ F, 2014).

É inegável a relevância do laudo pericial para o processo criminal, demonstrado por todos estes dispositivos legais. Chegar ao ponto de dizer que o processo criminal poderá ter atos nulos por conta da falta do laudo pericial é ressaltar sobremaneira a sua necessidade no conjunto probante (LIMA CJC, 2012). O processo é o script do serviço. O processo de produção do serviço começa com o acionamento da perícia pelo delegado de polícia, realizado por meio do Centro Integrado de Atendimento e Despacho na capital e pelas Delegacias de Polícia no interior. Após o acionamento, o perito identifica a natureza pericial, seleciona o material apropriado e se dirige para o local (VOSS C e ZOMERDIJK L, 2007).

A preservação do local é um fator crítico para o sucesso do trabalho pericial. Na sequência, o perito faz uma vistoria preliminar, elabora o seu plano de ação e faz as anotações. Busca os vestígios (impressões digitais, sangue, fios de cabelo, objetos, rachaduras, cadáveres, rompimento de obstáculos etc.) conforme o evento e os fotografa. Efetua as medições e desenha um croqui. Coleta os vestígios com a técnica apropriada, identifica-os e os preserva. Finalmente, libera o local. Retorna à seção de origem e registra o atendimento (JAMES SH e NORDBY JJ, 2005).

É comum, durante as investigações, a polícia solicitar para eventuais suspeitos o fornecimento de padrões (sangue, fio de cabelo, impressões digitais, caligrafia etc.), para que sejam comparados e analisados com aqueles vestígios que o perito criminal coletou no local. Esses exames são realizados no back office, centralizados na capital, porque são poucos os postos do interior que realizam alguns deles (RODRIGUES VR, et al. (2010).

Após a sua finalização, o laudo é encaminhado à Delegacia de Polícia, ou juízo, que o requisitou. Portanto percebe-se, que a Criminalística foi e nunca será um modismo, más uma imposição dos tempos. É que com o estágio de desenvolvimento alcançado pela Ciência Moderna, notadamente depois das contribuições de Newton estabelecendo a perfeita correspondência de suas teorias com os fatos observados, gerou-se a convicção de que os conhecimentos revelados pela física newtoniana eram objetivos, comprovados, perenes e inquestionáveis, pelo que se concebeu um caráter mecânico e previsível do mundo, instalando o paradigma newtoniano, disseminando a crença de que a ciência era o único meio de se alcançar a verdade, afetando a mentalidade, os valores e as regras de convivência entre os homens (ANDRADE JR, 2013).

\section{Criminalística na contemporaneidade}

Almeida AJR (1956), ratifica que a criminalística ou como mais conhecida, perícia criminal, hoje tem papel relevante na apuração das infrações penais, pois é por meio dela que se pontua a materialidade do crime e a forma de atuação do criminoso. Porém, muito se esperou para o seu devido reconhecimento como área do conhecimento, já que nos primórdios cabia à medicina legal a realização dos exames de integridade física do corpo humano, a pesquisa, busca e demonstração de elementos relacionados com a materialidade do fato tido como delituoso e o exame dos instrumentos do crime.

Como resultado, as agências de fomento federais e estaduais passaram a estabelecer áreas prioritárias de investimento para apoiar a maior parte da pesquisa e do desenvolvimento tecnológico realizado por instituições e universidades do país. Isso se reflete na estrutura da política de desenvolvimento científico e nas relações internas da comunidade científica (GARRIDO RG e GIOVANELLI A, 2011). 
Portanto, diante da competição entre grupos de pesquisa pelos recursos necessários para atender às suas necessidades, a alocação seletiva e criteriosa de recursos por instituições de fomento à ciência tem estimulado a adoção de práticas científicas cada vez mais rigorosas do ponto de vista metodológico. Por outro lado, o país passou a dar atenção à produção de recursos humanos cada vez mais qualificados, o que levou ao desenvolvimento de pós-graduações, e nestes cursos a formação e a criação científica tornaram-se indissociáveis (SERAFIM AB, 2004).

De acordo com Serafim AB (2004) universidades e instituições de pesquisa estão começando a estimular a criação de padrões de produtividade e a avaliação de trabalhos que levem a níveis de produção científica. Tudo isso teve um grande impacto na forma como a prática científica brasileira atual é moldada e na relação entre cientistas e outras instituições.

De acordo com o estudioso Morles V (2002), o método de pesquisa científica hoje adotado baseia-se no processo dedutivo de hipóteses, que tem características intencionais, sistemáticas e objetivas, compreendendo as seguintes etapas: observar a realidade; propor hipóteses; realizar observação controlada por meio de experimento e medição; teorizar ou combinar com outras hipóteses. Conecte-se com informações ou divulgue o conhecimento adquirido nas etapas anteriores. Este método é eficaz para pesquisas científicas muito rigorosas, nas quais as variáveis envolvidas podem ser controladas relativamente bem, como no caso de testes de laboratório. Portanto, é extremamente rigoroso em termos de adequação de procedimentos e ferramentas. Embora existam várias outras metodologias de pesquisa científica possíveis, elas são adotadas porque foram amplamente divulgadas e aplicadas nas ciências naturais que formam a base da medicina legal (MORLES V, 2002).

Portanto, segundo Morles V (2002), para ser considerada uma pesquisa científica, além do espaço de discussão e de crítica metodológica mediado por periódicos, congressos e seminários técnicos, é necessário também um meio de divulgação e consolidação de informações. Também destaca com algo essencial a formação é a preparação metodológica e prática do profissional, sendo efetuada mediante a instrução gradativa através de manuais e da leitura de artigos científicos (MORLES V, 2002).

Segundo Kuhn TS (1998), educação é um componente básico da chamada "ciência geral", que se define como uma tradição de pesquisa que perdura por um período de tempo e visa expandir o conhecimento em um campo específico, sem fugir da aceitação pela comunidade científica. Fato relevante para ser destacados são as condições de padronização dos métodos conforme afirma Marconi MA e Lakatos EM (2009) Este é um ponto crítico dentro da prática pericial, pois grande parte dos procedimentos adotados são uma mescla de técnicas rudimentares baseadas em antigos manuais e o uso do chamado "bom senso".

Para Brasil (2009):

"Essa situação não é específica de um estado, mas de todo o Brasil, tanto que o próprio governo federal, através do Plano Nacional de Direitos Humanos em sua diretriz, objetivo estratégico III propõe, dentre outras coisas: "c) padronização de procedimentos e equipamentos a serem utilizados pelas unidades periciais oficiais em todos os exames periciais." (BRASIL, 2009)

A julgar pela situação geral do Plano Nacional de Direitos Humanos, análises anteriores mostram que a prática especializada atual no Brasil carece de padrões científicos mínimos. Falta de padronização dos testes, sem esses testes não pode ser reproduzido (BRASIL, 2009)

Manuais tão caros para a prática científica são escassos ou mesmo inexistentes em alguns campos. Não há comunidade científica norteadora, portanto, não há possibilidade de crítica, correção de erros e possível modificação do método em função disso (KUHN TS, 1998).

Dessa forma, os especialistas acabaram repetindo o antigo método de comunicação oral sem muita discussão. Ou seja, o conhecimento profissional está intimamente relacionado à cultura local, na cultura local o conhecimento subjetivo continua, mas a possibilidade de ampliação da teoria e do método é muito pequena (LOBATO JÚNIOR JE, 2014). 


\section{CONSIDERAÇÕES FINAIS}

Pode-se levantar pelo conhecimento, que, o conteúdo sobre contexto histórico, o desenvolvimento sobre criminologia, sua prática pericial, e o seu estudo contemporâneo sobre a temática pesquisa nos leva a responder que o levantamento realizado propôs elucidar a abordagem do objeto histórico da criminologia. Um dado informativo importante que se deu é que no Brasil têm-se poucos grupos de pesquisa forense em áreas criminalísticas, no entanto vem aumentando nos últimos anos, mas mesmo assim ainda é um número inferior a outras áreas de pesquisa e ciências também. Tendo em vista a precária utilização de técnicas e conhecimentos sobre perfil criminal no Brasil, além de sua importância e relevância aplicada no âmbito investigativo, é necessário elaborar um aprofundamento técnico sobre a área criminal e maior difusão deste conhecimento.

\section{AGRADECIMENTOS}

Menções em agradecimentos as instituições de fomento à pesquisa; a Sociedade Brasileira para o Progresso da Ciência, SBPC, e a Sociedade Brasileira de Ciências Forenses, SBCF, que de alguma forma direta e/ou indireta possibilitaram para realização desta pesquisa.

\section{REFERÊNCIAS}

1. ALMEIDA AJR. Lições de Medicina Legal, $3^{a}$ ed. Rio de Janeiro: Editora Nacional de Direito, 1956.

2. ANDRADE JR. Importância do local de crime. 2013.

3. ARAÚJO LA. Ação Civil Pública Ambiental. $2^{2}$ ed. Rio de Janeiro: Lúmen Júris, 2004.

4. BRASIL. Programa Nacional de Direitos Humanos (PNDH-3). Secretária Especial de Direitos Humanos da presidência da República. Brasília: SEDH/PR. 2009.

5. BRAZ JAC. Investigação criminal. Leya, 2013.

6. BLUME A. Criminalística. Perito Crimina - PR. 2018.

7. CAPEZ F. Curso de Processo Penal. São Paulo: Editora Saraiva, 21aㅡ edição. 2014.

8. CODEÇO AG. Elementos básicos da perícia criminal. Rio de Janeiro: Lélu, 1991.

9. DOREA LE. Local de crime. Porto Alegre: Sagra-Luzzatto, 1995.

10. ESPINDULA A. et al. Local de Crime: isolamento e preservação, exames periciais e investigação criminal. $2^{\underline{a}}$ ed. Brasília: Alberi Espindula, 2007.

11. ESPINDULA A. Perícia Criminal e Civil: Uma Visão Completa para Peritos, Advogados, Promotores de Justiça, Delegados de Polícia, Defensores Públicos e Magistrados. Porto Alegre: Sagra Luzatto, 2002.

12. FRANÇA GV. de. Medicina Legal. Rio de Janeiro: Guanabar Koogan, 2001.

13. GARRIDO RG, GIOVANELLI A. Criminalística: origens, evolução e descaminhos. Cadernos de Ciências Sociais Aplicadas. Vitória da Conquista, BA. 2009.

14. GARRIDO RG, GIOVANELLI A. A Perícia Criminal no Brasil no Instancia legitimadora de Práticas Policiais Inquisitoriais. Revista do Laboratório de Estudos da Violência da UNESP/Marília. Edição 7. 2011.

15. GIALAMAS DM. Criminalistics. In: SIEGEL J, et al. (eds). Encyclopedia of Forensic Sciences. 2000; p.471-477.

16. GOMES H. Medicina Legal. Rio de Janeiro: Livraria Freitas Bastos, 1 ed., 1944.

17. JAMES SH, NORDBY JJ. Forensic Science: an introduction to scientific and investigative techniques. 2. ed. Florida: CRC, 2005.

18. KUHN TS. A estrutura das revoluções científicas. São Paulo: Perspectiva, 5ª edição, 257p. 1998.

19. LIMA CJC. A Modernização Organizacional da Criminalística Brasileira: uma proposta. Dissertação de Mestrado. Administração Pública da Escola Brasileira de Administração Pública e de Empresas da Fundação Getúlio Vargas. Rio de Janeiro - RJ. 85.f. 2012.

20. LINO D, MATSUNAGA LH. Perfil criminal geográfico: novas perspectivas comportamentais para investigação de crimes violentos no Brasil. Rev. Bras. Crimin. 7(1), 7-16, 2018.

21. LOBATO JÚNIOR JE. Padronização dos suprimentos utilizados nas maletas de local de crime dos institutos de criminalística do Brasil. Dissertação (mestrado) - Escola Brasileira de Administração Pública e de Empresas, Centro de Formação Acadêmica e Pesquisa. Fundação Getúlio Vargas - FGV. 2014.

22. MARCONI MA, LAKATOS EM. Metodologia científica. Editora Atlas - 5aㅡ edição, 312P. 2009.

23. MONAGHAN GP. Introdução. In: O'HARA, CE, OSTERBURG JW. Introdução à Criminalística. Rio de Janeiro: Fundo de Cultura S.A., 1964.

24. MORLES V. Sobre la metodología como ciencia y el método científico: un espacio polémico. Revista de pedagogía, 2002; 23(66), 121-146.

25. RABESCHINI AG. Criminalística forense. Revista Âmbito Jurídico. 2014. 
26. RABELLO E. Curso de criminalística. Porto Alegre: sagra luzzatto,1996.

27. RODRIGUES VR, et al. Perícia criminal: uma abordagem de serviços. Revista de gestão e produção. São Carlos, $2010 ; 17(4), 843-857$.

28. SEBASTIANY AP, et al. A utilização da Ciência Forense e da Investigação Criminal como estratégia didática na compreensão de conceitos científicos. Revista de Educação e química. vol.24 no.1 México. 2013.

29. SERAFIM AB. A Pós graduação no Brasil - Políticas de Desenvolvimento. IV Colóquio Internacional sobre Gestão Universitária na América do Sul. Florianópolis, SC. 2004.

30. VOSS C, ZOMERDIJK L. Inovation in experimental services - an empirical view. 2007.

31. ZARZUELA JL, ARAGÃO F. Química legal e incêndios. Porto Alegre: Sagra Luzzatto,1999. 